\title{
Connecting Reading and Writing: A Case Study
}

\author{
Zhanfang $\mathrm{Li}^{1}$ \\ ${ }^{1}$ College of Foreign Languages, North China Electric Power University, China \\ Correspondence: Zhanfang Li, College of Foreign Languages, North China Electric Power University, \\ Changping District, Beijing, China. E-mail: lzfleah@sina.com
}

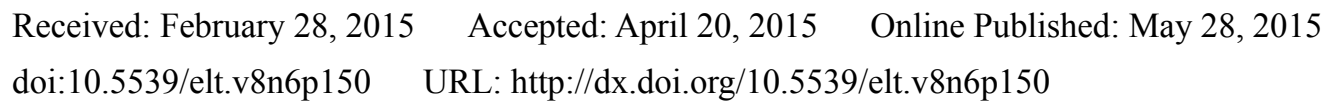

\begin{abstract}
Connecting reading and writing, proposed by many scholars, is realized in this case study. The 30 participants in this study are the English majors of the third year in one School of Foreign Languages in Beijing. They are encouraged to write journals every week, based on the source text materials in their Intensive Reading class, with the final piece as a reflective journal of their mind work in writing. All their journals written during the first 12 weeks of the whole semester are analyzed qualitatively. Analysis of their source-text-based journals shows that they have unique ways in integrating reading and writing, and the results of the reflective journals indicate that the participants have perceived the obvious merits of writing journals after reading. Journal writing helps them gain a better understanding of the source text, gives them a chance to review the text, cultivates their critical thinking abilities, and guarantees them a special opportunity to communicate with the teacher.
\end{abstract}

Keywords: connecting reading and writing, journal writing, critical thinking abilities

\section{Introduction}

The relationship between language by eye (reading) and language by hand (writing) has been recognized and studied (Berninger, 2002). One of the claims is that reading is "really writing" (actively creating meaning), and writing is "really reading" (passively finding what culture and history have inscribed in our heads), and weakness in reading often stems from neglect of writing (Elbow, 2004). Consequently the importance of combining reading and writing has always been emphasized and frequently discussed. Working with source texts is one of the most challenging of all academic literacy activities for L2 writers (Cumming, 2013), and the source text materials benefit writing in either knowledge telling or knowledge transforming (Hirvela \& Du, 2013).

Studies have already found that there is a close relationship between reading, writing and critical thinking. Scholars (Cavdar \& Doe, 2012; Gao, 2013) hold the view that reading widely can improve the learners' writing abilities, and in the process of writing, the logical thinking abilities will be enhanced. Critical thinking abilities include the abilities to organize "structures or elements of thought implicit in all reasoning" (Weissberg, 2013) or the abilities to find out the problems and then to provide the solutions (Saxton et al., 2012). All the values and competencies, like critical thinking, are socially constructed and highly situated within different disciplines (Condon \& Kelly-Riley, 2004), and the connection of reading and writing turns out to be one of the effective means of developing the language learners' critical thinking abilities. With their dual-identity, the student-readers first construct their own understanding of the source text materials on different levels, and secondly the student-writers reconstruct a new text from their own perspective, so meaning construction is the link between reading and writing (Gebhard et al., 2013).

The integration of reading and writing is theoretically admitted but practically neglected by most language teachers and language learners, especially in China (Mao \& Kou, 2014). Here we have a distinct division of the courses, so developing the students' reading abilities falls on the teacher of the Reading Class and cultivating the students' writing abilities is naturally the task of the Writing teacher. More significantly, we Chinese students are accustomed to accepting knowledge imparted by the teacher or the textbook (Xiao, 2004). In reading they are easily to accept blindly the author's ideas, and in writing they are more likely to follow certain formats. The aim of reading, to most of them, is to complete the Reading Comprehension task accurately, and the purpose of writing, to some of them, is to reiterate the commonly-agreed viewpoints on certain given topics. Most of them have no momentum to find certain topics they really want to delve deep into.

How to combine reading and writing and how to cultivate the students' independent thinking abilities frequently 
puzzled the English teachers who teach both Reading and Writing. Reading-to-write, a term taken from language testing studies, in contrast to writing-only (Plakans, 2008; Plakans \& Gebril, 2012, 2013), proves to be one of the options. The basic procedure of this model is that the students first read some materials of the target language, then find out the significant points, and finally state their opinions in the writing form from one perspective (Zhang \& Xi, 2012). While teaching both the courses of Intensive Reading and Academic Writing in one university of Beijing, we find that Reading-to-write is a useful model in either the reading class or the writing class ( $\mathrm{Li}, 2014)$. This paper is the report of an application of the model of Reading-to-write in our Intensive Reading Class (Advanced English), which is set for the English majors of the third year in one School of Foreign Languages. By analyzing the students' writing pieces after reading and their written introspections on their own writing processes, the present paper aims to find out 1) how they integrate reading into writing; 2) how writing facilitates reading and vice versa; and 3) what difficulties they would confront.

\section{Research Design}

For this course, like any other School of Foreign Languages in China, we choose the Advanced English edited by Zhang Hanxi and Wang Lili as our textbook, which is published by Foreign Language Teaching and Research Press. This textbook is popular in China for its wide coverage of topics, systematic arrangement of the materials, and timely adaptation. However, we cannot finish all the texts, so among the 15 pieces of the textbook, we studied six in the whole semester. In the past years, after we finished one text, we usually asked the students to write one essay on the definite title the teacher gave them, and sometimes the teacher asked them to write a summary. In this semester (August 2014-January 2015), a new teaching method is used. In class, we discuss the background, theme, figure of speech used in the text, extending our discussion into related fields. After class, the students are encouraged to write journals based on the source text materials as well as the topics in our class discussion, no words limitation and no style restriction.

Journal writing is adopted because it is kind of reflective practice, and for its "structural, holistic, and post-structural positions, respectively", it is important in language learning (Mannion, 2001), or as Montgomery (2001) claims, it is one effective strategy for developing the students' reading and writing skills. Every week the students are supposed to write freely on any self-selected topic, based on the main topics of the source texts or the subtopics we have further discussed in class.

\subsection{Participants}

All the students in the class were expected and encouraged to be the participants of this study, but finally four of them are excluded because of their frequent delay or absence of the writing. So the real participants are 30 among the 34 students attending the class. The first day of the course in the new semester, they were told of the teacher's plan to do a research on their writing, with the details revealed clearly at the end of the semester. The teacher promised to share with them the research result and they felt delighted and great honored if their words were quoted in the paper.

\subsection{Data Collection}

The participants are supposed to write one piece of journal every week (the first 12 weeks in a total of 16 weeks) and hand in their journals every two weeks. No definite title is given by the teacher. All but the final piece must be based on their reading of the source texts, with the final one being their written introspection of their journal writing process, which will offer the teacher-researcher ample opportunities to look into their thinking of the co-relationship between reading and writing.

\subsection{Data Analysis}

All the data are analyzed qualitatively. For the students' journals based on the source texts, the journal topics are given special attention, with our main purpose to see how the students derive a writing topic from their reading. And for the final introspective journals, the ideas receive adequate highlight and the real merits or the possible drawbacks of this journal writing process are our final penetration. Some words in the final pieces are quoted for the authentic reflections of their mind work in the whole journal writing process.

\section{Results}

The qualitative analysis of the data, both the journals on the source texts and the journals of their introspection, reveals some specific findings which are divided into the following categories.

\subsection{The Connection between Reading and Writing}

The importance of integrating source text into writing activities and its benefits for successful student-writers has been pointed out and emphasized by Plakans and Gebrial (2013), in which the higher scores are given to those 
who absorbed the ideas of the source texts and transformed them into their writing while the lower scores are given to those who only cited the words. We aim at the same goal in this paper. Language abilities and writing skills, though very important in language writing, will not be focused, but how they transform the ideas into their writing will be emphasized. Our special interest is on the students' mind working process in connecting their reading and writing, that is, in their reading process which aspect arouses their great interest or concern and later how they develop their own viewpoints in their writings. Therefore, the relationship between the original topics in the reading materials and the topics in their journal writing will be paid special attention to. The following six articles are chosen in our class for "both the content and style of the good writing" (Mayo, 2000) and the students only write journals on the previous five chosen texts because after we finish the last unit they are supposed to write a reflective journal of their mind work:

Table 1. Basic information about the source texts

\begin{tabular}{llll}
\hline Number & Title & Author & Style \\
\hline One & Hiroshima - the “Liveliest" City in Japan & Jacques Danvoir & Feature story \\
Two & The Trial That Rocked the World & John Scopes & Narrative \\
Three & Mark Twain -Mirror of America & Noel Grove & Feature article \\
Four & Everyday Use - for Your Grandmama & Alice Walker & Short story \\
Five & No Signposts in the Sea (Excerpts) & V. Sackville-West & Novel \\
Six & Speech on Hitler's Invasion of the U.S.S.R. & Winston S. Churchill & Political speech \\
\hline
\end{tabular}

Based on our chosen texts in this course, the topics of the 30 students' journal writings are roughly divided into four types: summary of the additional works related to the source text; further understanding of the text; language used in the text; and their reevaluation of some commonly-talked topics. The same or similar topics are not illustrated individually in the following charts.

\subsubsection{Summary of the Additional Works}

Summary is one of the commonly-used and reading-based methods in academic writing, in which the student-writers learn to express or create a new text based on the original text, without the change of meaning (Hood, 2008; Murray, 2013), and this transforming of the source text content into writing proves to be basic in academic writing procedure (Hirvela \& Du, 2013). Motivated and propelled by our class discussion of some additional works by the author or the related works the teacher recommends to them, five students finish reading the original works after class and write summaries on these additional reading materials. The novels or short stories they read and wrote on are Dombey and Son, Benjamin Button; Growth Ring; Pride and Prejudice; The Spirit of Chinese People; Tom Sawyer; Is He Living or Is He Dead.

In this way, they extend their reading to some related fields and enlarge their horizons. Writing drives them to read more and reading provides them with the basic ideas for writing. So reading and writing are closely integrated.

\subsubsection{Further Understanding of the Text}

Besides the few summary writings on the additional reading materials, most students write about their further understanding of the source texts, revealing their attitudes and opinions of the original text from different perspectives. The specific topics of their writing and the connection between the topics of their writing and those of the source texts are as follows:

Table 2. The source texts from different perspectives

\begin{tabular}{lll}
\hline Texts & Writing Topics & Connection \\
\hline $\begin{array}{l}\text { Hiroshima-the "Liveliest" Japan } \\
\text { Cn the Bombing of Hiroshima } \\
\text { Hiroshima: the City and Its People } \\
\text { Shame Culture }\end{array}$ & General reflection of the text \\
& "Losing Face" in Chinese Culture & $\begin{array}{l}\text { Elaboration on one subtopic } \\
\text { Understanding of "shame culture" } \\
\text { in the context of China }\end{array}$ \\
\hline
\end{tabular}




\section{Face Theory}

The Trial That Rocked the World

Ideas on Evolution

Understanding of the Bible

Mark Twain-Mirror of Mark Twain: the Writer and the Writing America

Everyday Use-for Your Maggie vs Dee Grandmama
Understanding of "shame culture" from the perspective of linguistics

Elaboration on one subtopic

Analysis of the main character

Analysis of the main characters

Elaboration on one subtopic

\subsubsection{Language Used in the Text}

When studying The Trial That Rocked the World, the various figures of speech arouse some students' great interests. One of them makes a detailed study of the rhetorical devices used in it; one takes pun as a focus to elaborate its role in the text; one analyzes the beauty of language from a broad perspective; and another one even ventures to analyze the relationship between language and a person's social identity. They produce the following pieces of writing:

Table 3. Language features in the source texts

\begin{tabular}{lll}
\hline Text & Writing Topics & Connection \\
\hline $\begin{array}{l}\text { The Trial That } \\
\text { Rocked the World }\end{array}$ & $\begin{array}{l}\text { Rorld" } \\
\text { Pun in "The Trial That Rocked the World" }\end{array}$ & $\begin{array}{l}\text { from thes in "The Trial That Rocked the perspective of } \\
\text { rhetorical devices }\end{array}$ \\
& $\begin{array}{l}\text { The Beauty of Language } \\
\text { The Relationship between One's Language and } \\
\text { Character }\end{array}$
\end{tabular}

\subsubsection{Reevaluation of Some Common Topics}

Most students prefer writing about their own emotions concerned with some extended topics. Seeing the relationship between the mother and daughter in the story of Everyday Use-for Your Grandmama, they start to talk about this kind of relationship in their daily life, and some of them even talk about their own mother-daughter relationships. Some others, extending their thinking beyond the subtopics we encounter in the source texts, begin to talk about some big topics like life, hope, money, religion, war, failure or success. The following are their specific written topics:

Table 4. Extension of the source texts

\begin{tabular}{|c|c|c|}
\hline Texts & Writing Topics & Connection \\
\hline $\begin{array}{l}\text { Hiroshima-the "Liveliest" City } \\
\text { in Japan }\end{array}$ & War and Peace & Elaboration on one subtopic \\
\hline The Trial That Rocked the World & $\begin{array}{l}\text { Faith and Religion } \\
\text { Scandal and Truth } \\
\text { The unfairness of law }\end{array}$ & Elaboration on one subtopic \\
\hline Mark Twain-Mirror of America & Knowledge and Reading & Elaboration on one subtopic \\
\hline $\begin{array}{lll}\text { Everyday } & \text { Use-for } & \text { Your } \\
\text { Grandmama } & & \end{array}$ & $\begin{array}{l}\text { Mother-daughter Relationship } \\
\text { Forgetting and Forgiving }\end{array}$ & Elaboration on one subtopic \\
\hline $\begin{array}{l}\text { No Signposts in the Sea } \\
\text { (Excerpts) }\end{array}$ & $\begin{array}{l}\text { Life and Money } \\
\text { Worries and Hopes in Life } \\
\text { Failure and Success } \\
\text { Cooperation and Pressure }\end{array}$ & Elaboration on one subtopic \\
\hline
\end{tabular}


From the comparison between the titles of the source texts and the topics of the students' writing, we can see that the original reading materials provide them with the basic ideas or clues for their writing, which evidences that extensive reading enhances writing (Sun, 2014). We also find that writing helps them a lot in understanding better of the original texts. Due to writing, they are impelled to read more, to understand the text in depth and even to appreciate the text from a fresh perspective. More importantly, the integration of reading and writing makes them think critically about some common topics which used to be taken for granted by most of them.

The modality of language output affects language learners' cognitive performance (Grabowski, 2010). Journal writing, based on the reading materials instead of what happened in their daily life, is a special type of language output. To know what mental work is really involved in this unique language output, the participants' reflective journals will be analyzed in the following two sections. Their words will be quoted to show their views of both the merits and the frustrations they experienced in writing journals.

\subsection{The Merits of Writing Journals}

Cathy is one of those who had a firm belief of the close relationship between reading and writing. "I think writing is a process in which you explore your own ideas." she reveals, "It is a way for you to find yourself. Only when I'm familiar with the topic can I compose a content-abundant essay. Reading is really of great importance to writing". Angela also realizes that "I need to read more original works and accumulate more useful phrases" in order to write well. She admits that she has learned a lot through writing the journal, because she "tried different topics and found something really beneficial". Roki says in her journal, "Writing is absolutely a good thing. We read something and then we write something. This is a process from perception to expression." She further realizes that her difficulty in writing is because of her inadequate reading, "Sometimes I didn't know how to start a theme. My writing proficiency is low. There are no highlights in my expression. I think that all these may be because of my lack of reading".

All these suggest that reading is a process of input and writing is a process of output, and the importance of the integration of these two processes is obvious (Li Jimei, 2013). Writing journals based on the source materials requires reading or rereading which leads to learning because noticing "helps learners identify the linguistic features they need and facilitates subsequent learning of these features" (Hanaoka, 2007).

There are still some other merits of writing. Vocabulary acquisition is one important aspect in language learning and has received enough emphasis. Karen puts it out that "it (writing journals) can help us learn some new words and phrases", and she is even surprised at her own progress in self-correcting the mistakes in her writing, which never occurs before. Besides this, Queen claims that "it gives me an opportunity to calm down and think deeply regularly". More importantly, Angela admits that "I gradually begin to think in English with no translation between the two languages, which greatly improves the speed of writing". To summarize the various merits of writing journals, we can read Sophia's detailed revelation on it:

Generally speaking, I think it is very useful and happy to write journals. When I write something, I care less or even no attention to my handwriting, grammar or spelling, but I care more about my thoughts and emotions that I am going to convey. I can express my feeling after class and simultaneously review what we have learnt. Journal makes me fond of searching for information. In order to fulfill the assignment, I have to gather information of the writer and something else. For example, I have finished the Color Purple and part of Tom Sawyer. I can say that journals drive me to read.

All in all, the major benefits of writing journals can be roughly divided into the following types.

\subsubsection{To Help the Students Better Understand the Source Texts}

Learning to write is undoubtedly the target of most second language writers while "writing to learn" (Zhang, 2013) is proved in this study. Ellen is one of those who agree that "it (writing journals) can help us to utter our thoughts about the text", and Shirley proposes more clearly that "in this process, I would surely get familiar with much more extracurricular knowledge as well as a better understanding of the whole text and the author's purpose". Iris holds the same opinion that "I have to read the article in every detail to find some topics, which made me better understand our text". Emma provides a detailed explanation of her mind work in this whole process:

Writing journal lets me write some English essays every week. It also lets me think more about the texts. I usually search information on Internet, such as the story and the author's background. I try to understand which idea the author wants to express. During this process I can know more about the author and have a better understanding [of the text] than before. 


\subsubsection{To Help the Students Review the Text}

Writing enhances reading, not only in the sense of "memorizing some new words" as Cindy mentions, but also in terms of the necessity of a preliminary better understanding of the original text. Cathy makes it more clear that "to write it, we must review the text first, and then write down my feeling and understanding towards it. It is a good way for us to force ourselves to read the article, and listen carefully at class". Carol points out the importance in writing journals as the following:

We tend to put more emphasis of these figures of speech instead of the deep meaning of the essay. Therefore, the habit of writing journals after finishing every essay gave me a chance to explore the main idea, the significance and the true aim of the essay, which lead me to think more about life, war, culture, human characters and so on.

This is a good response to Thompson et al. (2013), which claims that electing and incorporating source materials effectively into academic writing requires students not only to be familiar with the defined areas of disciplinary content, but also be able to represent themselves through their writing as articulate and authoritative authors.

\subsubsection{To Cultivate the Students' Critical Thinking Abilities}

In the context of higher education [the same for the other levels], the set of values and competencies of critical thinking the teachers commonly attempt to promote in the students is extremely complex because they are socially constructed and highly situated within different disciplines (Condon \& Kelly-Riley, 2004). However, we still intend to promote it, at least to encourage the participants' independent thinking abilities in choosing the topics. Through the students' reflective journals, we find that they have realized the importance of thinking in the writing process. Just as Clover claims, "If we want or need to write something, it's inevitable that we need thinking", or as Vicky reveals, "Keeping journals pulls my thoughts together and tempers my mind through practice". Alice recalls that "writing every week helps me have a brain storm, making me know how to think". Candy vividly tells us in what sense writing can promote thinking:

Thinking plays an essential role in man's life and I could not help thinking when I write an essay, which in turn can change my attitude and opinion towards life, nature, world even people around me. Only when I begin to compose an essay, can I understand why I should be a college student to receive higher education.

\subsubsection{To Communicate Further with the Teacher}

We have never thought about using writing to solidify the relationship between the teacher and the students. Tina expresses her feelings in her journal clearly that "I can express my idea about the text which I have no chance to say in class. It is also a good way to communicate with my teacher about my idea of the text or my life, my plan". Tina's words make me realize that class communication is inadequate sometimes. For those introvert students, whom the teacher is likely to neglect, writing journals after class gives them an opportunity for the teacher to know their learning as well as their feeling.

While the functions of writing are emphasized by the participants in their reflective journals, there is no mention of the functions of the source texts in their writing, which are disclosed by their writing and found by others as shaping the writers' opinions about the topic, providing ideas on the topic, supporting the writers' opinions and serving as a language source (Plakans \& Gebrial, 2013).

\subsection{The Students' Frustration in Writing}

Though most students have realized the importance of integrating reading and writing, those who merely take journal writing as a task or homework have not perceived the significance of this connection. Some even feel bored because they think that the source texts are hard to understand. This proves that source text materials should be comprehensive to help the student-writers in their writing (Plakans \& Gebrial, 2013). Some others complain that they could write better journals if the teacher can let them write anything not only about the text. And there are still some others who have no self-confidence of keeping it as a good habit. In a word, several students really have complaints and doubts concerned with this type of journal writing.

\subsubsection{What to Write}

Among those who are troubled by writing journals, some do not know which aspect they should choose so they have no idea of what to write. This is partly because, as Iris says in her journal, they are accustomed to writing essays with certain topics given by the teacher. Susan talks about another reason, that is, the stories in their textbook are really far from their life, so they are not interested in reading the stories, not mention writing on a topic derived from it. Queen mentions when she was studying the text in class she had a lot of ideas, but she couldn't recall those ideas any more after one week. Shirley claims "there are so many details, many of which can become a starting point. It is hard for me to choose one among them". Cathy puts it more clearly in details: 
Sometimes writing is annoying for me, because I cannot find a proper topic. I know there are many choices. News, texts or books all provide me with lots of topics. But I always prefer to choose the topics on which I can easily find my stand. I think that I should find some topics with which I am not familiar and try to think out something new.

From Cathy's words, we can see that she is intensively involved in a thinking process which she herself has not identified. This is very important in language learning, especially in cultivating the language learners' critical thinking abilities. That she is not satisfied with her topic choice for its shallowness just proves that she is making a great progress.

\subsubsection{How to Express the Ideas}

Having decided what to write, there is still the question of how to organize the ideas and express them accurately. As Joy worries, "Sometimes I have many ideas in my mind, but I don't know how to show it on paper. Or even if I have decided what to write, it might go to a wrong way in the middle." Vicky writes quite clearly that "after I made up my mind of what to write, there came a question of the layer of structure". Meat thinks that her obvious problem in writing journals is "there is no certain logic".

How to express the ideas properly really perplexes some of the students. Maybe this is because, as Ellen says, their English level is poor. They may express their opinions fluently in Chinese, but they cannot write many words to express their opinions in English. Just as Zhang (2013) discovered, English writing is different from Chinese (their native language) writing, because these second language writers have to develop a new-self and think in a new way, which is evidenced in that "their (the student-writers) essays in Chinese are clear and cogent, but once the ideas are rendered into English according to the original structure, the argument and points made in support of the structure become elusive, lacking cohesion and coherence". Candy describes her mind picture vividly in her journal:

I often struggle to find a reasonable and natural word or sentence which serves as a transition. It is obvious that my vocabulary is very limited. I cannot express my ideas exactly because my vocabulary limits my imagination. The biggest obstacle for me is that I cannot express my opinion suitably in English. I have many thoughts in my mind, but due to the lack of proper words and the so-called English logic, I invariably found that my writing was not able to reflect the exact meaning of my mind. When I wanted to transfer it to the words, there was suddenly a blank in my mind. That setback completely disturbed my enthusiasm of writing.

So in teaching reading, language teacher's conscious emphasis on form as well as meaning is important. Reading only provides the potential possibility for writing and how to write well requires the intake of both the language proficiency and the writing skill, which usually come after persistent reading and conscious noticing (Qi, 2014). Sometimes using reading materials as the model for writing may lead the students to conscious noticing (Chen, 2000), which is emphasized by Yang and Zhang (2010) in exploring the role of reformulation after writing and a model text offered by a native writer in EFL students' writing performance.

\section{Conclusion}

From what we discussed above we can see that all of the participants have realized the importance of connecting reading and writing. Most of them really enjoyed the writing process, because they did not have to squeeze their thoughts to find something to cater to a given topic, and they learned to express themselves on the topics they really prefer. They are practicing the theory of "writing to mean" (Gebhard et al., 2013). More importantly, some students realized that in order to make a good choice of the topic, they need to think deeply. This consequently cultivates their critical thinking abilities.

Though the students' language ability is not focused in this paper, we accidentally find that there is a close relationship between the students' language abilities and their attitudes towards journal writing. The higher-level students are neither frustrated by the self-selection of the writing topic nor the writing. The middle-level students do not feel it difficult to decide what to write but they are disturbed by how to write it. Those few students who are at a relatively lower level are troubled by the choice of the writing topics, so they prefer writing on a given topic.

The implications of this study upon language teaching can be best explicated as the following. First, the integration of reading and writing is undoubtedly applicable in either class activities or after-class assignments. Secondly, there exist big individual characteristics among language learners, so their learning differences should be taken into account. Thirdly, conscious noticing on form besides meaning is also required. Fourthly, positive assessments and sincere encouragements should be given to language learners, especially to those who are frustrated by writing. 


\section{References}

Berninger, V. W. et al. (2002). Reading and Writing: Connections between Language by Hand and Language by Eye. Journal of Disabilities, 35(1), 39-56.

Cavdar, G., \& Doe, S. (2012). Learning through Writing: Teaching Critical Thinking Skills in Writing Assignments. PS: Political Science and Politics, 2, 298-306.

Chen, L. P. (2000). Using Models in Teaching English Composition. Journal of PLA University of Foreign Languages, 23(6), 67-69.

Condon, W., \& Kelly-Riley, D. (2004). Assessing and teaching what we value: The relationship between college-level writing and critical thinking abilities. Assessing Writing, 9, 56-75. http://dx.doi.org/ 10.1016/j.asw.2004.01.003

Cumming, A. (2013). Assessing integrated writing tasks for academic purposes: Promises and Perils. Language Assessment Quarterly, 1, 1-8.

Elbow, P. (2004). Putting writing before reading is an effective approach to teaching and learning. Educational Leadership, 5, 8-13.

Gao, Q. P. (2013). The Development of Chinese English Majors' Thinking in Argumentative English Writing. Beijing: Foreign Language Press.

Gebhard, M. et al. (2013). Teaching to mean, writing to mean: SFL, L2 literacy, and teacher education. Journal of Second Language Writing, 22, 107-124. http://dx.doi.org/ 10.1016/j.jslw.2013.03.005

Grabowski, J. (2010). Speaking, writing, and memory span in children: Output modality affects cognitive performance. International Journal of Psychology, 45(1), 28-39. http://dx.doi.org/10.1080/ 00207590902914051

Hanaoka, O. (2007). Output, noticing, and learning: An investigation into the role of spontaneous attention to form in a four-stage writing task. Language Teaching Research, 11(4), 459-479. http://dx.doi.org/10.1177/ 1362168807080963

Hirvela, A., \& Du, Q. (2013). "Why am I paraphrasing?”: Undergraduate ESL writers' engagement with source-based academic writing and reading. Journal of English for Academic Purposes, 12, 87-98. http://dx.doi.org/ 10.1016/j.jeap.2012.11.005

Hood, S. (2008). Summary writing in academic texts: Implicating meaning in processes of change. Linguistics and Education, 19, 351-365. http://dx.doi.org/10.1016/j.linged.2008.06.003

Lee, H.-J., \& Lim, C. (2012). Peer Evaluation in Blended Team Project-based Learning: What do Students Find Important? Educational Technology and Society, 15, 214-224.

Li, J. M. (2013). Reading and Writing: The Gap between Input and Output. Shaanxi Jiaoyu (Gaojiao), 12, 55-57.

Li, Z. F. (2014). Reading-to-write: A Practice of Critical Thinking. The Journal of Arts and Humanities, 5, 67-71.

Mannion, G. (2001). Journal Writing and Learning: Reading between the structural, holistic, and post-structural lines. Studies in Continuing Education, 23(1), 95-115.

Mao, J. S., \& Kou, J. (2014). The Impact of English Reading upon English Writing. Journal of Hubei University of Economics (Humanities and Social Sciences), 11(6), 186-192.

Mayo, L. (2000). Making the Connection: Reading and Writing Together. The English Journal, 89(4), 74-77.

Montgomery, W. (2001). Journal Writing: Connecting Reading and Writing in Mainstream Educational Setting. Reading \& Writing Quarterly, 17, 93-98.

Murray, R. (2013). 'It's not a hobby': Reconceptualizing the place of writing in academic work. Higher Education, 1, 79-91.

Plakans, L. (2008). Comparing composing processes in writing-only and reading-to-write test tasks. Assessing Writing, 13, 111-129.

Plakans, L., \& Gebrial, A. (2013). Using multiple texts in an integrated writing assessment: Source text use as a predictor of score. Journal of Second Language Writing, 22, 217-230. http://dx.doi.org/10.1016/ j.jslw.2013.02.003

Plakans, L., \& Gebril, A. (2012). A close investigating into source use in integrated second language writing 
tasks. Assessing Writing, 7, 18-34. http://dx.doi.org/10.1016.j.asw.2011.09.002

Qi, G. H. (2013). Rethinking the Relationship between Reading and Writing. Journal of Jixi University, 11, 85-87.

Saxton, E., Belinger, S., \& Becker, W. (2012). The Critical Thinking Analytic Rubric (CTAR): Investigating intra-rater and inter-rater reliability of a scoring mechanism for critical thinking performance assessments. Assessing Writing, 17, 251-270. http://dx.doi.org/ 10.1016/j.asw.2012.07.002

Sun, P. (2014). Exploring the English Teaching Methods of Reading for Writing. Overseas English, 1, 58-59.

Thompson, C., Morton, J., \& Storch, N. (2013). Where from, who, why, and how? A study of the use of sources by first year L2 University students. Journal of English for Academic Purposes, 12, 99-109. http://dx.doi.org/10.1016/j.jeap.2012.11.004

Weissberg, R. (2013). Critically Thinking about Critical Thinking. Acad. Quest, 26, 317-328.

Xiao, L. Q. (2004). The Wrong Region of English Language Teaching in China. Foreign Language Teaching, 1, 67-71.

Yang, L. X., \& Zhang, L. (2010). Exploring the role of reformulations and a model text in EFL students' writing performance. Language Teaching Research, 14(4), 464-484. http://dx.doi.org/ 10.1177/1362168810375369

Zhang, L. J. (2013). Second language writing as and for second language learning. Journal of Second Language Writing, 22, 446-447. http://dx.doi.org/10.1016/j.jslw.2013.08.010

Zhang, Z. F., \& Xi, X. J. (2012). Project-Based Learning and Its Application (A). Advances in Education Research (C). Information Engineering Research INST, USA, 233-236.

\section{Copyrights}

Copyright for this article is retained by the author(s), with first publication rights granted to the journal.

This is an open-access article distributed under the terms and conditions of the Creative Commons Attribution license (http://creativecommons.org/licenses/by/3.0/). 